\title{
Dengue Fever: Ophthalmological Perspective
}

\author{
Hernandez-Delgado MA (D, Salvador-Galvez B and Valdez-Garcia JE* (D)
}

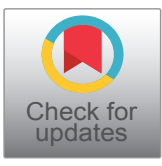

Instituto Tecnológico y de Estudios Superiores de Monterrey, Monterrey, Nuevo Leon, Mexico

*Corresponding author: Jorge Eugenio Valdez-García, Institute of Ophthalmology \& Visual Sciences at Zambrano Hellion Medical Center, Av. Batallon de San Patricio No. 112, San Pedro, Nuevo Leon, 62670, Mexico; Tel: +52-81-82-59-07-79

\begin{abstract}
Dengue fever is a highly prevalent zoonotic disease. This virus endangers 3.9 billion people, with no less than 390 million infections annually. Dengue has a broad spectrum of clinical manifestations; from completely asymptomatic to life threatening complications. This review discusses the relevance of dengue in current medical practice as well as the scarcely known ophthalmological complications. We aimed to first describe the epidemiology, viral characteristics, transmission and global distribution, classification of disease, systemic manifestations and treatment. Secondly, the ophthalmological findings, prognosis and complications associated with dengue fever. This is a literature review of dengue virus infection with an ophthalmologist's perspective. 97 publications were used to synthesize the most important points in the vast knowledge on dengue, and its ocular findings. Complications vary from relatively benign skin petechiae and subconjunctival hemorrhage, to life threatening conditions such as shock syndrome. Ocular complications of dengue may occur as late as 5 months after infection resolution and have severe visual consequences. Closely examination of patients with dengue and early detection of ocular findings may result in better clinical outcomes. Further research is needed to determine the precise moment and regimen strategies for achieving successful visual and systemic outcomes.
\end{abstract}

\section{Keywords}

Dengue, Ocular findings, Diagnosis, Ophthalmology, Dengue detection

\section{Abbreviations}

DF: Dengue Fever; DENV: Dengue Virus subtypes 1 to 4; LMIC: Low and Middle Income Countries; RNA: Ribonucleic Acid; NS1: Non-Structural Protein 1; NS2A: Non-Structural Protein 2A; NS2B: Non-Structural Protein 2B; NS3: NonStructural Protein 3; NS4A: Non-Structural Protein 4A; NS4B - Non-Structural Protein 4B; NS5: Non-Structural Protein 5; WHO: World Health Organization; Rtpcr: Real Time Polymerase Chain Reaction, ELISA: Enzyme-Linked
Immunosorbent Assay; HI: Haemagglutination Inhibition; NMOSD: Neuromyelitis Optica Spectrum Disorder; MFS: Miller Fisher Syndrome; GBS: Guillain Barré Syndrome; OCT: Optical Coherence Tomography, DRT: Diffuse Retinal Thickening; CME: Cystoid Macular Edema

\section{Introduction}

Dengue Fever (DF) it's a febrile disease caused by one of the four Dengue virus subtypes (DENV's 1-4). Its transmission occurs during the capillary blood consumption of Aedes aegypti or Aedes albopictus [1-3]. Primary infection may be asymptomatic or ranging from mild febrile disease up to extremely life-threatening shock syndrome. Numerous host factors, viral determinants and vector characteristics influence the clinical outcome and severity of this infection. The scope of this review lies with the ophthalmologic signs and symptoms, complications and prognosis associated with DF.

\section{Epidemiology}

Dengue is endemic to 128 nations, it prevails in low and middle income countries (LMIC) where it endangers 3.9 billion people annually [4]. Approximately 390 million dengue infections occur every year $[5,6]$. The Indian subcontinent is the epicenter and many cases go undiagnosed and unaccounted for [7].

\section{Dengue Virus}

Four DENV subtypes are associated with clinical disease. They belong to the Flaviviridae family, and are specified as follows: DENV-1, DENV-2, DENV-3 and DENV-4 $[8,9]$. The viral genome consists of a positive sense RNA of about $11 \mathrm{~kb}$ in length that encodes for three structural proteins (capsid, premembrane and

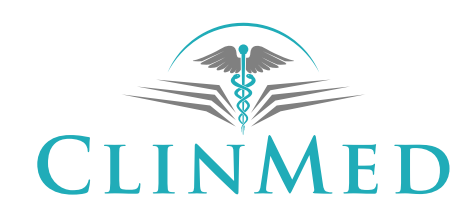

INTERNATIONAL LIBRARY
Citation: Hernandez-Delgado MA, Salvador-Galvez B, Valdez- Garcia JE (2021) Dengue Fever: Ophthalmological Perspective. Int J Trop Dis 4:047. doi.org/10.23937/2643-461X/1710047

Accepted: April 22, 2021; Published: April 24, 2021

Copyright: (C) 2021 Hernandez-Delgado MA, et al. This is an open-access article distributed under the terms of the Creative Commons Attribution License, which permits unrestricted use, distribution, and reproduction in any medium, provided the original author and source are credited. 
envelope) and 7 non-structural proteins (namely; NS1, NS2A, NS2B, NS3, NS4A, NS4B, and NS5) [4]. Despite the fact that there are four different DENVs, none of them provides an adequate immunologic response to protect from reinfection of other subtypes for more than a few months. This is particularly important in endemic regions where multiple strains and reinfection represent significant public health challenges. Primary dengue infection refers to the first wild-type DENV the patient's organism encounters. Secondary infection refers to any DENV subtype after that, which infects the patient. Secondary dengue infections are very important because they often lead to severe dengue and worse clinical outcomes, especially if they occur after 18 months of the first one $[10,11]$.

\section{Aedes as vectors}

Aedes aegypti, Dengue's primary vector, reproduces near human settlements or near their boundaries. Eggs are laid in freshwater bodies where they initiate fast growing cycles $[12,13]$. These mosquitoes fester at night and are able to puncture the human flesh multiple times in order to satisfy their appetite. Although their flight distance may be short, one Aedes spp with DENV could be able to infect several individuals within the same household $[14,15]$. Aedes mosquitoes are distributed between latitudes $45^{\circ} \mathrm{N}$ and $35^{\circ} \mathrm{S}$, these represent mainly tropical and subtropical areas. While Dengue virus is transmitted through this mosquito species, so is Yellow Fever and Chinkungunya. In fact, both of them represent important public health concerns $[16,17]$.

Aedes albopictus are also important Dengue vectors, both in natural and experimental conditions [18]. They are more tolerant to low temperatures and have a wider geographic distribution [19]. Despite this, they are not the main source of dengue transmission due to their less frequent eating habits. Endemic outbreaks are far less common with this Aedes species [17].

\section{Transmission cycle}

Endemic and epidemic transmission is produced by human-mosquito-human cycles [12]. Virus spread through mosquitoes and non human primates has been demonstrated in Southeastern Asia and Africa. Nonetheless, it does not readily serve as an important reservoir [20]. Infection occurs after female Aedes spp mosquito festers on capillary vessels and DENVs are released by their salivary glands. Then, the virus commences its replicating functions that lasts approximately from 4 to 13 days that are accompanied by fever and general malaise $[16,21,22]$. In this phase, viral loads in the host's plasma are in sufficient numbers for being contagious to other non-infected mosquitoes shall they fester on the host. Incubation period in Aedes spp ranges from 8 to 12 days, after this time period the DENVs can be effectively transferred to humans and be infectious during the entire lifespan of the mosquito.

\section{Atypical dengue transmission}

Dengue virus can be transmitted by blood inoculation (needle puncture, transfusion, etc...) and mucocutaneous exposure [23]. Infected blood donors may be asymptomatic depending on the virus incubation [24]. Whereas this fact is a relevant form of transmission is unknown [25]. Dengue transmissibility by blood containing derivatives lies approximately at $37 \%$.

Vertical transmission has been described in some case reports [26]. If the mother contracts dengue 10 days prior to labour, this infection may be present in the neonate 4 to 11 days after birth. However, contrary to the common belief, dengue does not increase its incidence or severity [27]. Immunoglobulin M effectively protects and has been associated with the $1.6 \%$ vertical transmission rate [28].

\section{Aedes aegypti recognized global distribution [29]}

(Figure 1, Figure 2 and Figure 3) [30]

\section{Dengue Fever}

\section{Classification}

The latest World Health Organization (WHO) dengue classification was made in 2009. It includes the following categories; dengue without warning signs, dengue with warning signs and severe dengue [31]. Dengue without warning signs can be diagnosed after fulfilling the residence or travel criteria in an endemic area, plus fever and 2 of either; nausea/vomiting, rash, headache, eye pain, muscle ache, joint pain, leukopenia or a positive tourniquet test. Dengue with warning signs include the previous described diagnosis plus any of the following; abdominal pain, persistent vomiting, fluid accumulation (ascites, pleural effusion, pericardial effusion, etc...), mucosal hemorrhage, lethargy, restlessness, $>2 \mathrm{~cm}$ hepatomegaly, hematocrit increase with thrombocytopenia. The diagnosis of severe dengue is made when there is at least one of the following critical conditions; shock, fluid accumulation that leads to respiratory failure, clinically relevant hemorrhage, Aspartate aminotransferase or Alanine aminotransferase enzyme $\geq 1000 \mathrm{u} / \mathrm{L}$, impaired consciousness or organ failure. Furthermore, dengue without warning signs has two clinically evident phases; febrile and convalescent. While severe and dengue with warning signs have three well described phases; febrile, critical and recovery phases [31].

\section{Systemic signs and symptoms}

More than 360 million DENV infections happen every year. From this impressive number, approximately 96 million of these (24.6\%) are clinically present [5]. Most of the clinically apparent dengue infections are diagnosed in adults, they are slightly less frequent in children in whom the infection usually presents asymptomatic [32]. 


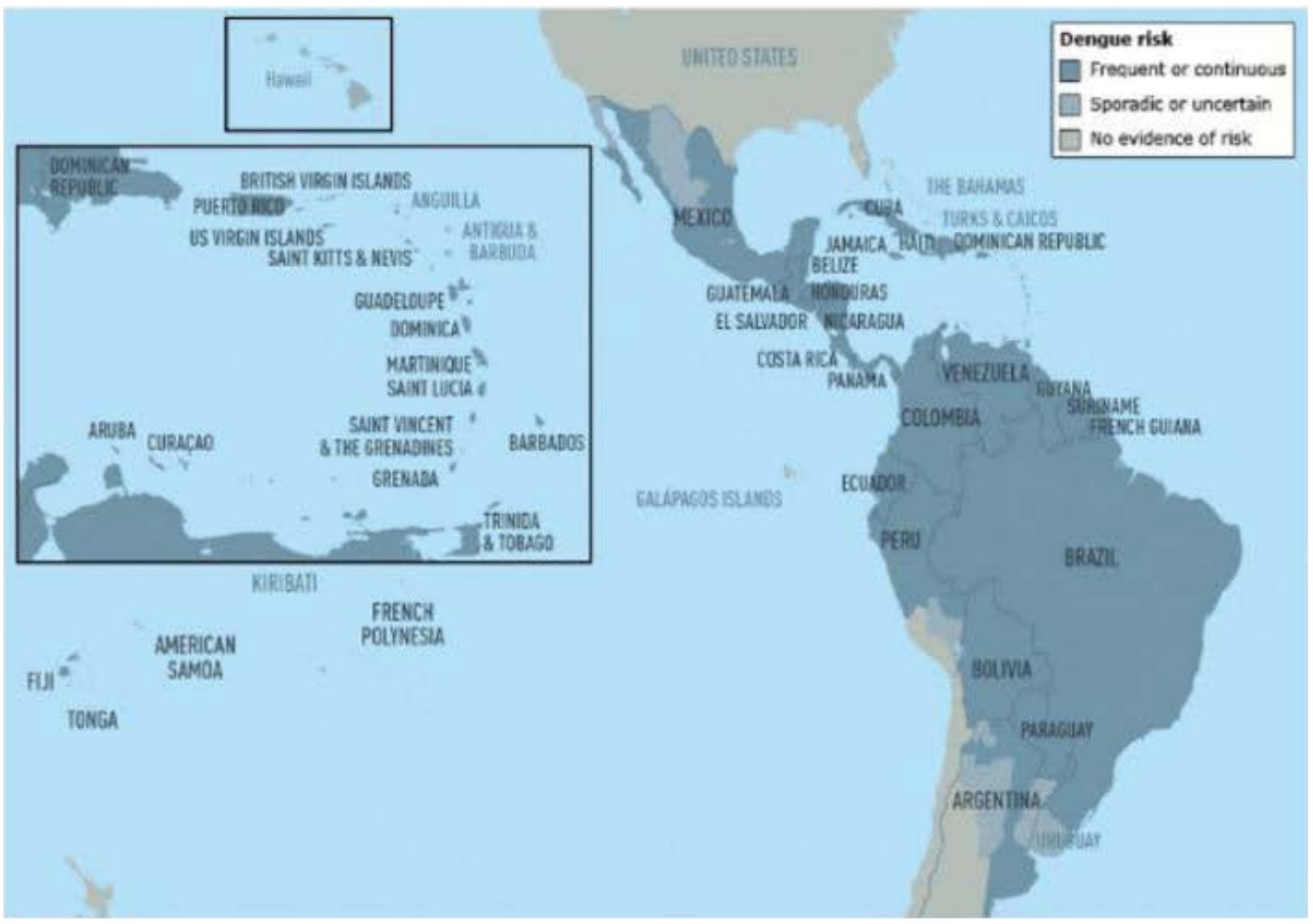

Figure 1: Dengue risk and distribution in the Caribbean and Central and South America [30].

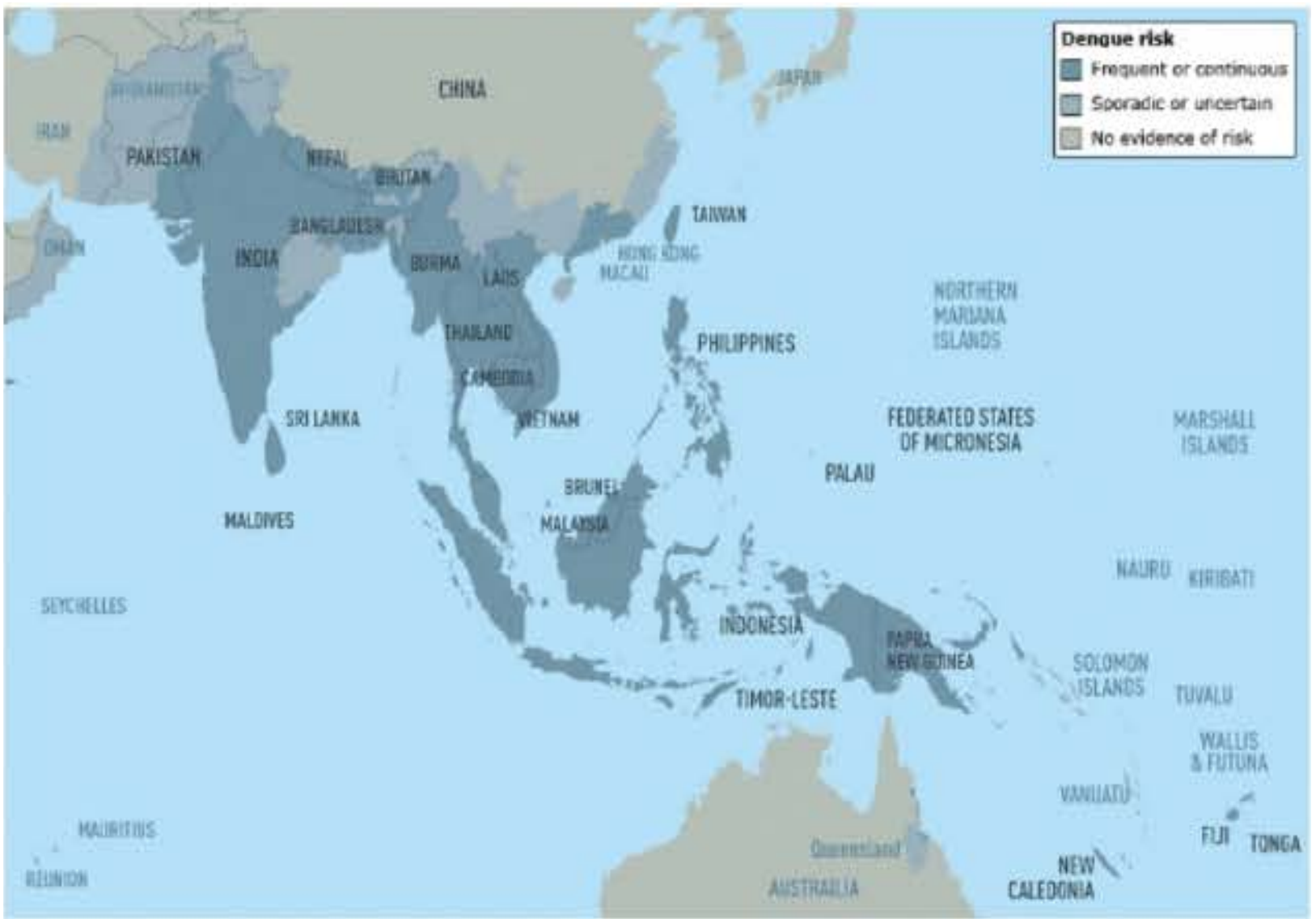

Figure 2: Dengue risk and distribution in Asia and Oceania [30]. 
Symptoms take place within the first 4 to $7 \mathrm{sev}$ en days after the mosquito bite [22]. The first dengue phase (febrile) presents as high fever, headache, nausea, vomiting, arthralgias, anorexia, diarrhea, cough, nasal congestion and macular rash $[33,34]$. In patients that develop dengue with warning signs, the critical phase is characterized by hemorrhage, either mucosal or gastrointestinal. The most concerning of these may be as dangerous as hematemesis, profound menstrual bleeding, melena and uncontrolled epistaxis. It is important to mention that roughly $20 \%$ of infections transcur symptomatically [35].

Diagnosis from systemic signs and symptoms: Clinical diagnosis may be challenging depending on the symptoms or clinical stage. Depending on where the patient has travelled or lives there can be several differential diagnoses [36]. Early stages resemble a "flu-like" disease such as measles, Zika virus, Chinkungunya virus, Malaria, yellow fever, rhinovirus, parainfluenza virus or influenza [31]. Later stages may present relatively benign or severe, thus early accurate suspicion and diagnosis is essential.

Febrile phase typically characterizes high grade fever, myalgias, arthralgias, retro-orbital pain, facial erythema, photophobia and cephalea [37,38]. A positive tourniquet test may help differentiate dengue from other viral etiologies. The tourniquet test is executed by an inflated cuff between the systolic and diastolic blood pressure of the patient's arm for five minutes. Petechiaie may be seen distant to the cuff after that and they must be counted. A positive test can be declared if they exceed more than 20 per square inch area $[39,40]$. It is important to note that in some cases the febrile phase could be accompanied by stronger hemorrhagic symptoms such as gastrointestinal bleeding and epistaxis [31]. Furthermore, the severity of this phase is not predictive of severe dengue progression and jealous monitoring of additional signs and symptoms is crucial [31].

For those unfortunate to enter the critical phase of Dengue infection, develop warning signs and symptoms mostly related to plasma leakage. This deleterious condition is produced by a steep reduction in white blood cells along with platelets that often happens four days after high fever reduction (patients temperature approximate 27.5 - 38 Celcius) $[38,41]$. Plasma leakage may last up to 48 hours, hematocrit levels and fluid status must be closely monitored to prevent further deterioration [38]. Abdominal ultrasound may reveal free fluid in the peritoneal cavity or chest [42]. Warning signs precede hypovolemic shock (sometimes in a manner of hours) and its profound consequences in metabolic state, coagulation and organ impairment [43]. Therefore, the significance of this 48 hours in diagnosis and prevention of severe dengue is paramount $[35,43,44]$.

After this phase, the patient's fluid status recovers exponentially, renal and cardiovascular function re- establishes, appetite increases and fever diminishes $[44,45]$. A "recovering rash" can be seen in some cases, this rash predominates in the chest and back area with white patches surrounded by erythematous skin [45].

Severe dengue can be suspected if the patient presents with severe plasma leakage leading to shock, respiratory distress, major haemorrhage and/or organ failure [31]. If shock appears a few days after fever (at "defervescence") could be linked to an immune-mediated pathology [46]. Patients with Dengue shock syndrome evolve from an asymptomatic plasma leakage to a life threatening hypovolemic shock with cardiac failure $[47,48]$.

Laboratory diagnosis: Technological development has led to an oversum of diagnostic laboratory tests, including: host response to virus, virus or viral products [36]. Virus isolation is done by cultivating blood samples into mammalian (Vero, BHK-21 and LLCMK2) or mosquito cells (CLA-1, AP61, AP64, Tra-284 and C6/36) [49]. Even though this vigorous process may take days or even weeks, results are absolute [50].

Reverse-transcription polymerase chain reaction (rtPCR) can provide efficient diagnosis in hours, $[50,51]$ the disadvantage lies in the availability of specialized equipment and standardization methods [52,53].

DENV serology offers many laboratory tests: Enzyme-Linked Immunosorbent Assay (ELISA) for capturing IgM and IgG, Hemagglutination Inhibition (HI), complement fixations, Indirect Immunofluorescent antibody tests and Western blot. The most commonly available tests are IgG and IgM ELISAs and HI [36]. As a matter of fact, $\mathrm{HI}$ was the gold standard of laboratory diagnosis for many years despite having the great disadvantage of being virtually unable to distinguish from other flaviviridae infections (Yellow Fever, West Nile virus, Zika virus, Japanese encephalitis, Tick-borne Encephalitis disease) $[54,55]$. Consequently, ELISA for IgM and IgG has become the most used serological test. The viremic phase is short so early disease onset and high IgM titers point to a confirmatory diagnosis [54]. IgG does not appear in early primary infection, but on secondary dengue infection rapid increase can be observed [36].

Specific NS1 protein capture tests are also a sensible and specific marker for disease, mainly because NS1 protein is released by infected cells and can be detected in the first 9 days of disease onset [36]. This NS1 number can even be related to the viral titer, $[56,57]$ and is even related to plasma leakage [58]. Furthermore, NS1 $\geq 600 \mathrm{ng} / \mathrm{ml}$ in secondary infections can be predictive of severe dengue disease [46].

Combination assays have led to a more concrete laboratory diagnosis using a small blood sample with an approximate sensitivity of $68.9-93.9 \%$ and specificity of $72.5-98.75 \%[54,59,60]$. 


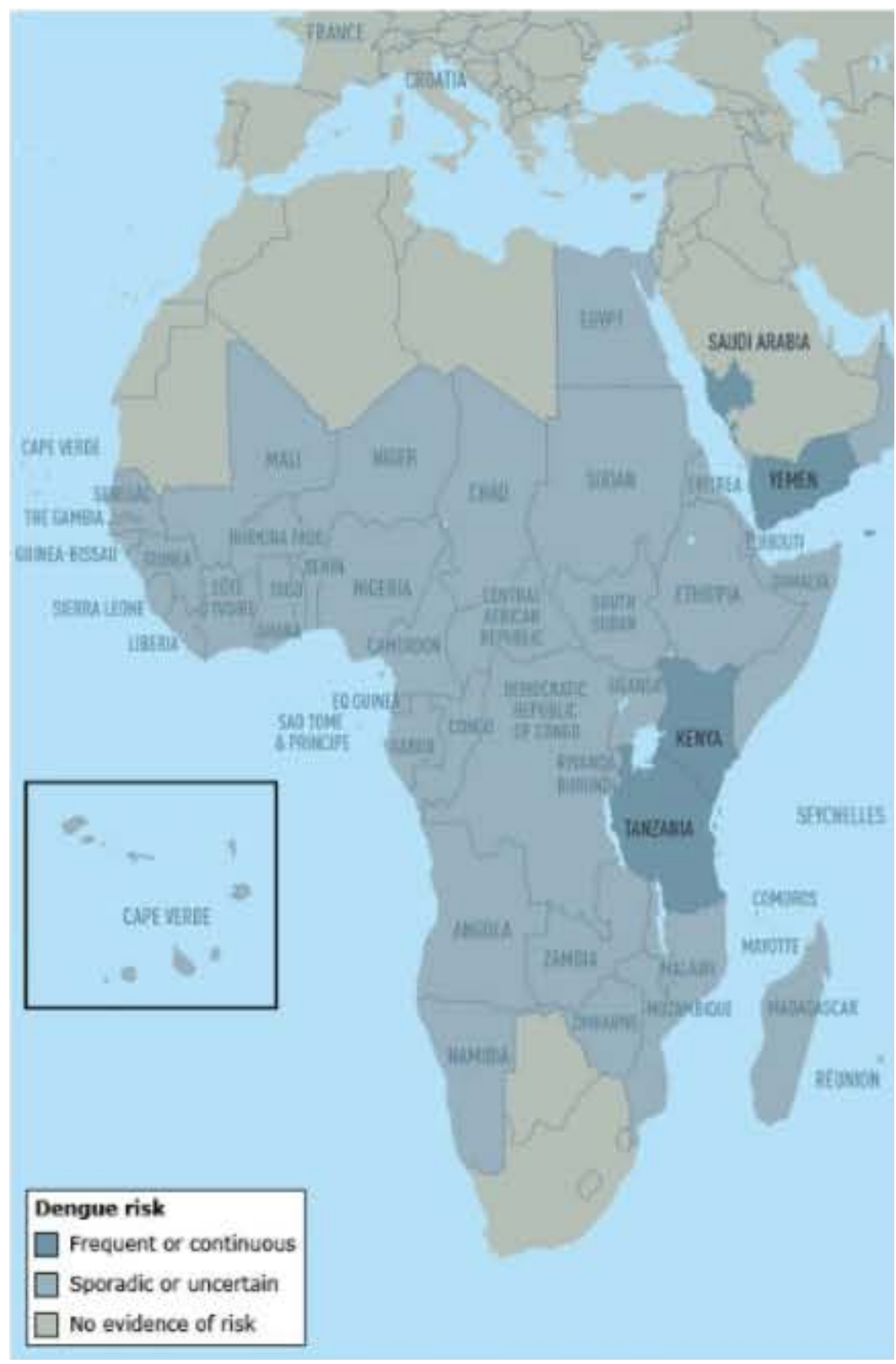

Figure 3: Dengue risk and distribution in Africa and the Middle East [30]

Treatment: There is no specific antiviral therapy for dengue virus. Symptom-based therapy is prescribed for the clinical manifestations depending on the gravity of the infection; bed rest, intravenous or oral hydration, antipyretic drugs or non-steroid anti-inflammatory drugs is given. On the contrary, severe dengue may require hospitalization, complete blood count analysis, transfusion, urine output measurement, intravenous fluid therapy, continuous blood pressure and vital signs measurement [4].

\section{Ocular signs and symptoms}

Dengue's ophthalmologic manifestations may be unilateral or bilateral, predominantly the former $[61,62]$. They appear between 2 and 150 days after infection and their incidence approximates 5-6\% of dengue cases $[63,64]$. Nonetheless, the majority of these appear after thrombocytopenia (about the seventh day of fever commencement) [64]. Commonly referred signs and symptoms include: visual fatigue (30\%), periorbital and retro-orbital pain (20\%), blurred vision (10\%), diplopia $(3 \%)$, foreign body sensation (3\%), photopsias (2\%) and myodesopsias (1\%) [65]. Subconjuntival haemorrhage can also be found after thrombocytopenia [63].

The most common clinical ocular features are; macular haemorrhage $(69 \%)$ and oedema $(77 \%)$, retinal vasculitis $23.1 \%$, intermediate uveitis $12.3 \%$, posterior vitreous cells $10.8 \%$, anterior uveitis $7.7 \%[66,67]$ (Figure 4).

Subconjunctival hemorrhage: Independently of platelet count, subconjunctival hemorrhage presents in up to 8 and $60 \%$ of cases [68,69]. Incidence is greater in patients requiring intensive care unit and increases with worsening thrombocytopenia, particularly if less than $50,000 / \mathrm{ml}$ platelets $[67,70]$ (Figure 5 ). 


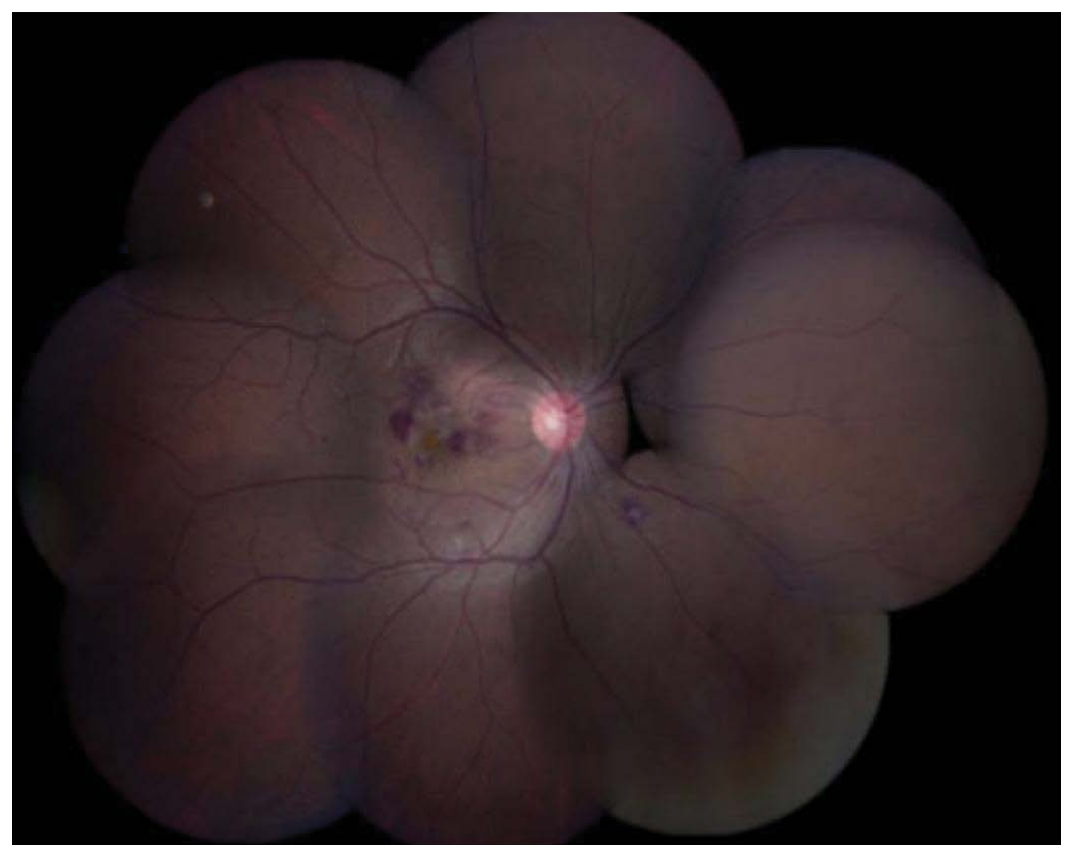

Figure 4: A fundus photo of a patient who had dengue fever and blurring of vision in the right eye showed intraretinal hemorrhage, cotton wool spots, macular edema confined to the macula, and a yellow-orange spot at the fovea [67].
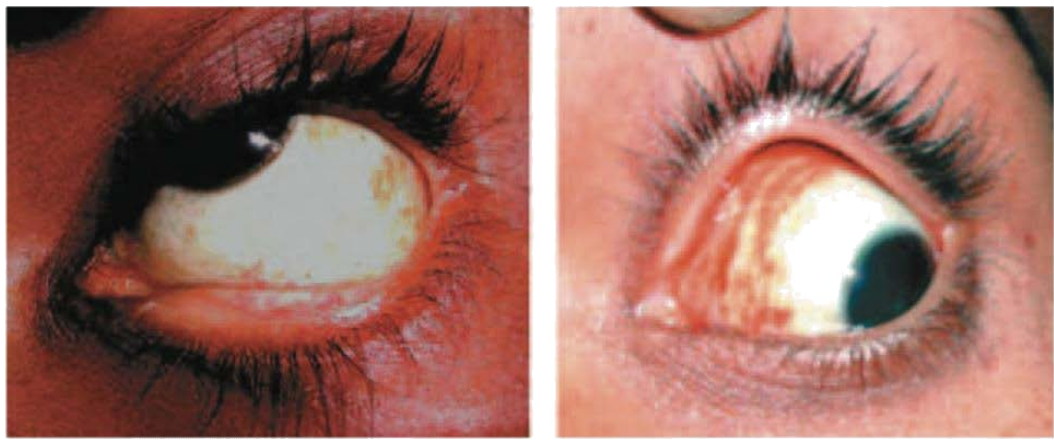

Figure 5: Left: Petechial type of subconjunctival haemorrhage; Right: Diffuse type of subconjunctival haemorrhage [69].

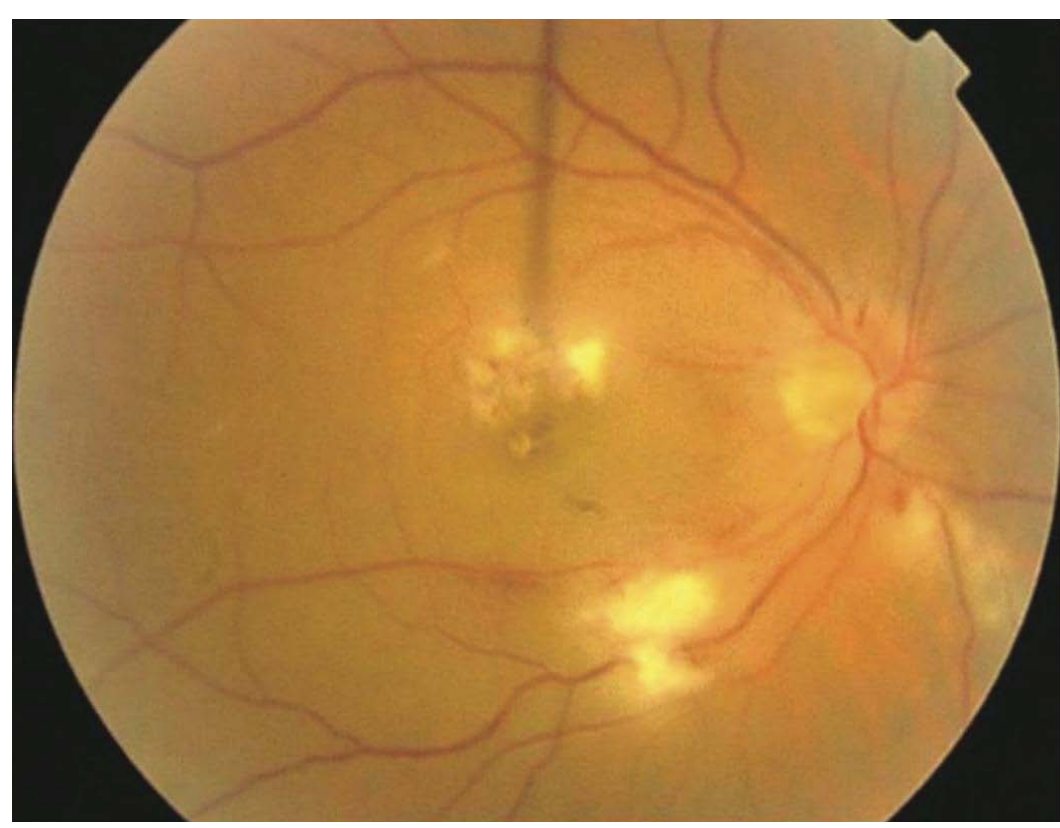

Figure 6: A 32-year-old male with a history of blurring of vision in both eyes one week following febrile illness showing multifocal areas of retinochoroiditis, with cotton-wool spots and retinal hemorrhages in the right eye [74]. 
Uveitis: Quite rarely does anterior uveitis is presented because of dengue fever, only about $7.7 \%[64,66,71]$. It can be a result of active infection or be present as late as 3-4 months. If present, it is usually unilateral. One particular feature of dengue's anterior uveitis is the scarce ciliary congestion despite anterior segment inflammation, and that all sizes of keratic precipitates can be found [72]. Intermediate uveitis is present in approximately $12.3 \%$ of cases and can co-occur with anterior uveitis in $11 \%$. Adequate steroid response is reported in such cases $[66,71,73]$.

Posterior uveitis is the most frequent uveitis in respect to the abovementioned types. Its clinical presentation is vast; retinochoroiditis, neuroretinitis and retinitis. Retinochoroiditis may be focal or multifocal with or without associated macular involvement [74] (Figure 6).

Unilateral panuveitis combined with branch retinal artery occlusion can occur in the following five months after dengue infection [75]. The precise mechanisms by which dengue causes uveitis is unknown, it is theorized that low C3 and C4, as well as autoantibody production in ocular tissues leads to all the anterior and posterior pole manifestations [69,76-78].
Neuro-ophthalmologic manifestations: Neurological manifestations of dengue virus are seldom, and their pathophysiologic basis not fully comprehended $[79,80]$.

Despite being quite rare, several cases of bilateral and unilateral optic neuropathy have been reported in the literature after dengue virus infection [71,80-86] (Figure 7).

Furthermore, neuromyelitis optica spectrum disorder (NMOSD) has also been reported. In fact, DENV-1 has been positively associated with NMOSD despite presence or absence of anti-Aquaporin 4 antibodies. Concluding that dengue infection triggers NMOSD's clinical symptoms [87-89]. Steroid treatment resulted in successful resolution in all reported cases.

Miller Fisher syndrome (MFS), a rare variant of Guillain Barré syndrome (GBS) caused by preceding viral or bacterial infection can also be attributed to dengue virus $[79,90,91]$. Classic MFS triad includes ophthalmoplegia, ataxia and areflexia [92].

Vascular occlusions: Dengue virus is also causative of vascular occlusions even in absence of severe disease. The host response to infection is the determining factor, rather than a direct viral effect $[76,93]$. Thrombocytope-
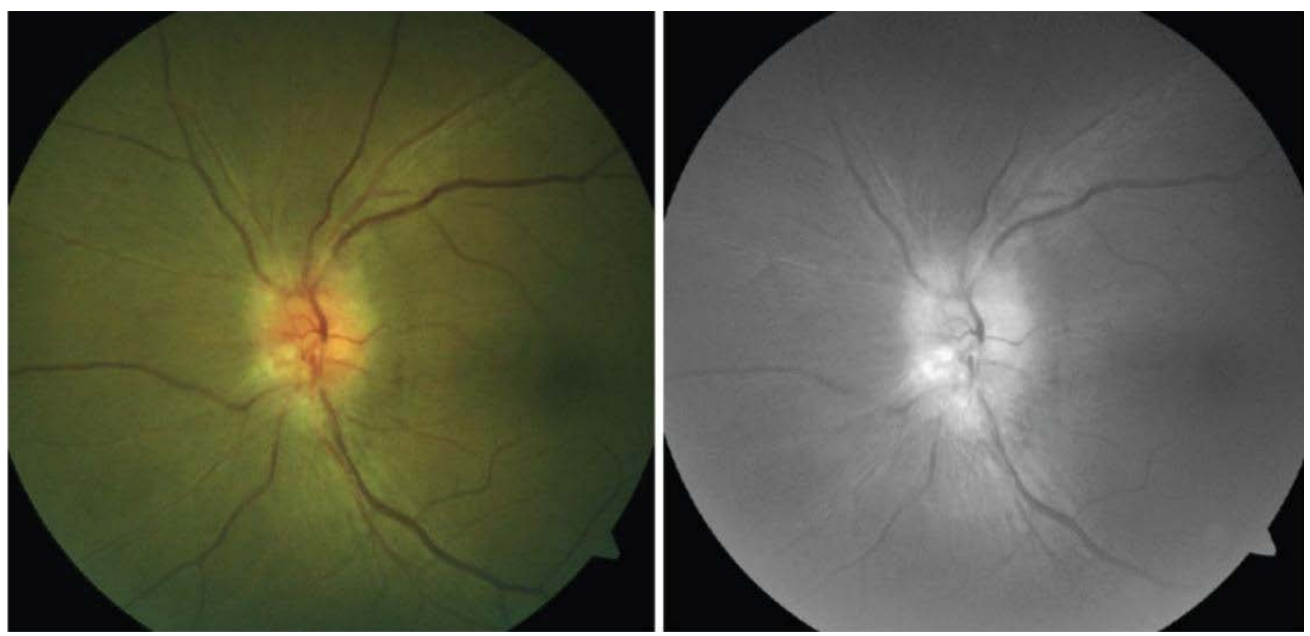

Figure 7: Left: Pallid disc edema with obliteration of the cup; Right: Red-free photograph of the same eye with an anterior ischemic optic neuropathy following dengue infection [83].
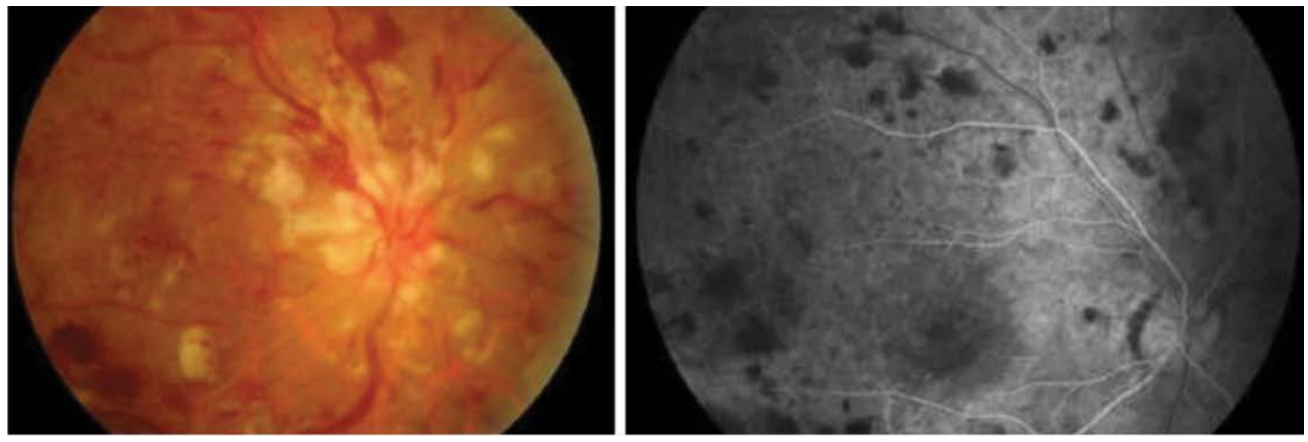

Figure 8: Left: Fundoscopy reveals dilated tortuous veins, retinal hemorrhages, optic disc edema, and cotton wool spots around the disc corresponding to a central retinal vein occlusion. Right: Fundus fluorescein angiography of the same eye shows delayed venous filling [94]. 
nia is also a common feature of dengue infection, nonetheless the inflammatory procoagulant state is often overlooked [94]. Reported occlusions happened even five months after infection, and even though arterial occlusions are far more common, vein or combined occlusions may be found [75,94,95] (Figure 8 and Figure 9).

Maculopathy: The concern behind maculopathy associated with dengue fever is that many patients do not recover adequate central vision and scotoma remains even after resolution on OCT (optical coherence tomography [96]. Maculopathy may be serotype dependent (particularly DENV-2) [97]. Approximately $70 \%$ of patients present some degree of maculopathy, but only do $10 \%$ of patients have macular associated symptoms [77]. They usually appear seven days after fever onset, but they may appear up to 30 days later [71].

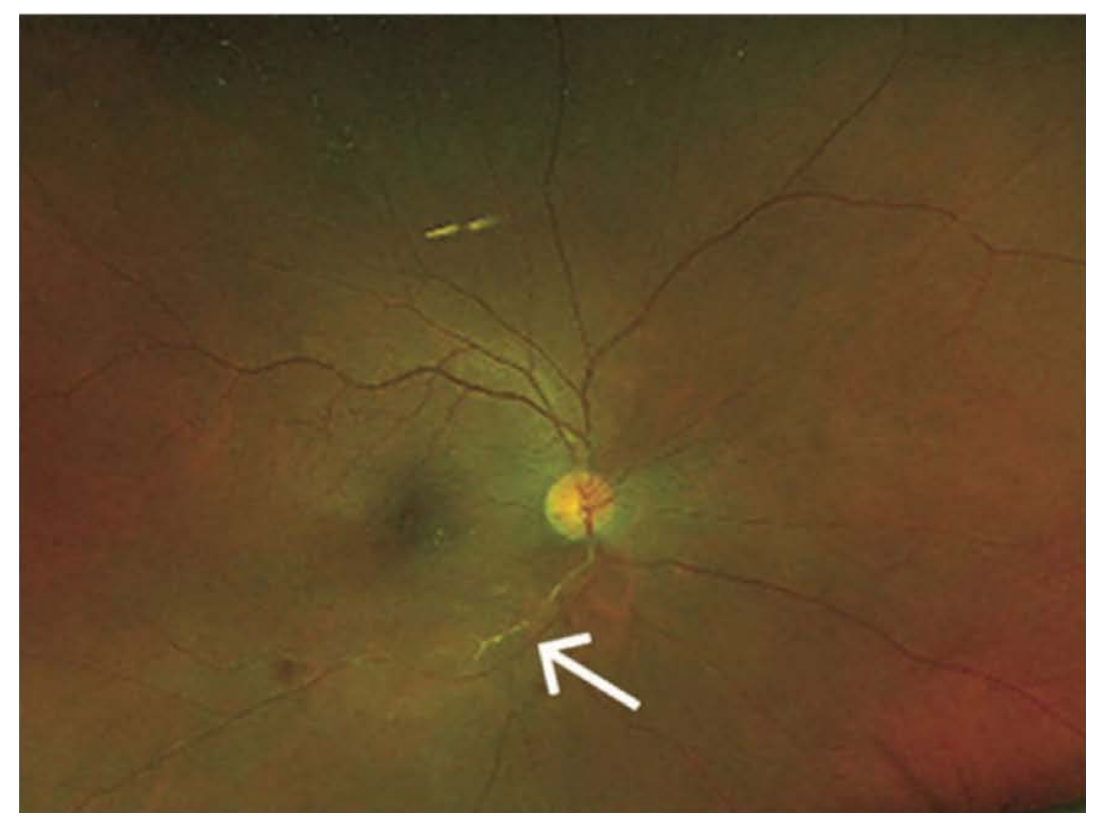

Figure 9: Wide field color fundus photo of the right eye showing retinal hemorrhages, retinal opacification inferior macula and sheathing of inferotemporal branch of retinal artery (white arrow) [75].

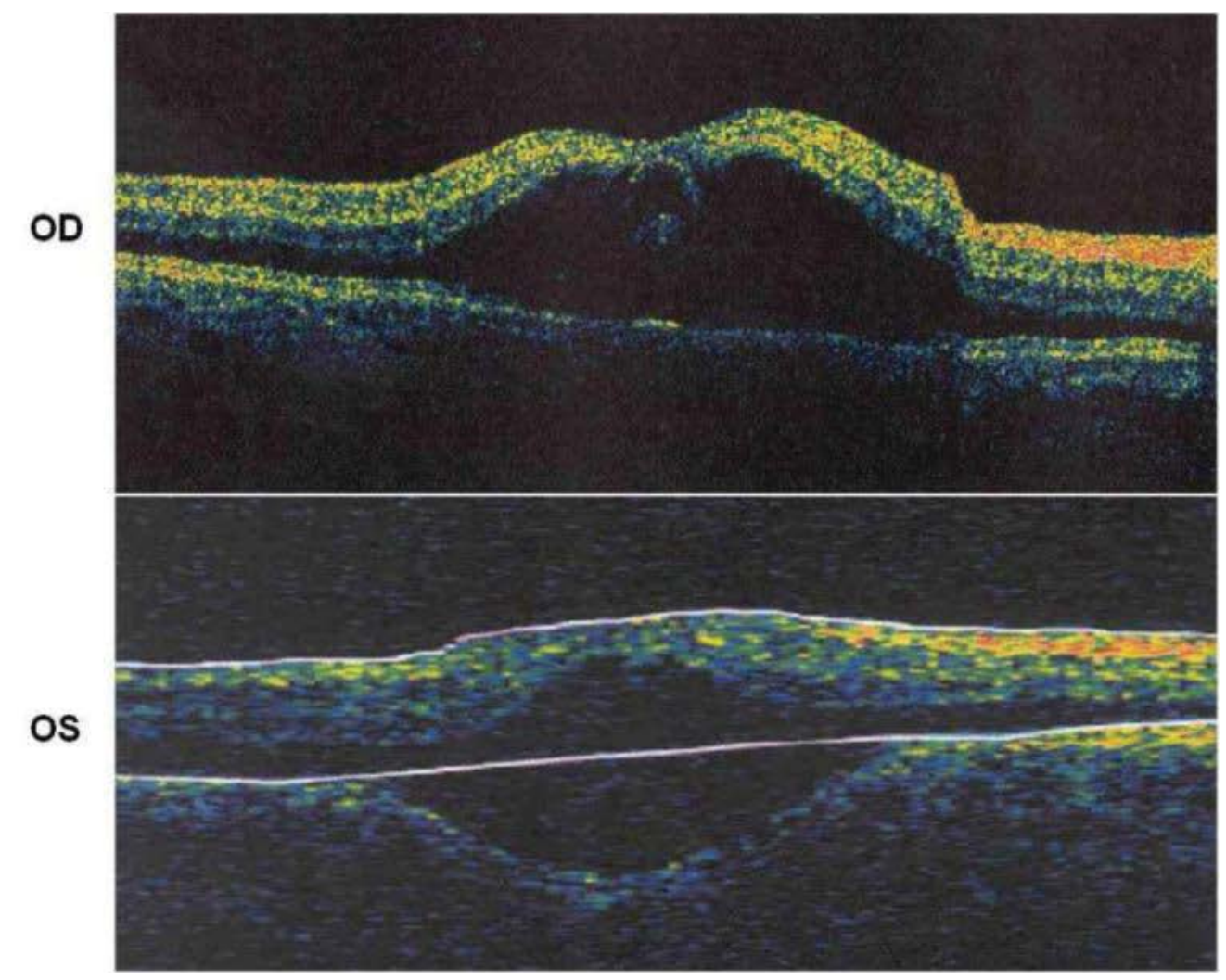

Figure 10: OCT imaging of the maculae showing severe maculopathy with edema [63]. 
Findings include; intraretinal and flame hemorrhages, macular edema and retinochoroiditis along paramacular and macular regions (Figure 10).

Dengue maculopathy is divided in three types according to Teoh, et al. depending on their OCT patterns: 1) Type 1 - diffuse retinal thickening (DRT), 2) Type 2 - cystoid macular edema (CME), 3) Type 3 - Foveolitis with or without macular oedema. Type 1 (44.6\% of cases) had the best prognosis of them all. Patients with type $2(21.6 \%)$ and $3(33.8 \%)$ had central scotoma, with type 3 being far more detrimental for visual acuity and poor resolution. The use of OCT helps in determining the extent of macular affectation after dengue infection. However, it does not necessarily correlate with clinical outcomes and visual acuity. Despite the average 4 week maculopathy resolution on OCT, $59.5 \%$ of patients presenting this complication had remaining central/paracentral scotoma that persisted for nearly 2 years [96]. The other concern is that anti inflammatory treatment has little effect on changing clinical outcome $[63,64]$ (Figure 11, Figure 12 and Figure 13).

Treatment: As stated before, there is no specific antiviral therapy. Ophthalmological intervention must be related to ocular findings. Subconjunctival hemorrhages resolve in a couple of weeks. Steroid therapy may be used in cases of uveitis or optic neuropathy. In vein occlusions antiangiogenic agents may be applied. Severe central nervous system involvement may require a multidisciplinary approach, including the use of intravenous steroid or immunoglobulins. Maculopathy may resolve without intervention or may require intravitreal antiangiogenic agents. So far, no clinical trials of steroid ther-

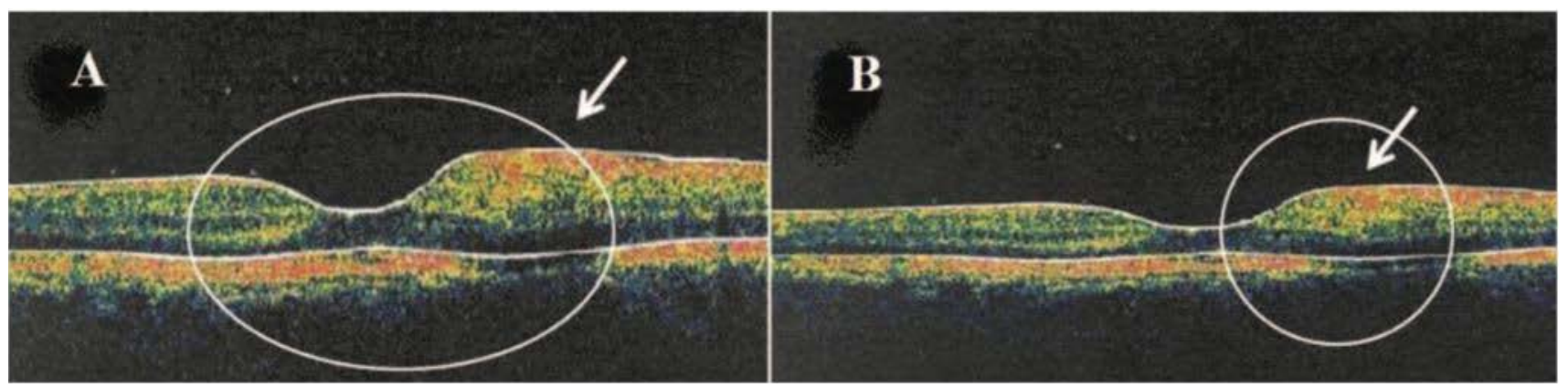

Figure 11: A) Left: Horizontal OCT scan obtained through the fovea of a patient showing Type 1 DRT in a paracentral region; B) Right: Solid arrow indicates a localized retinal thickening [96].
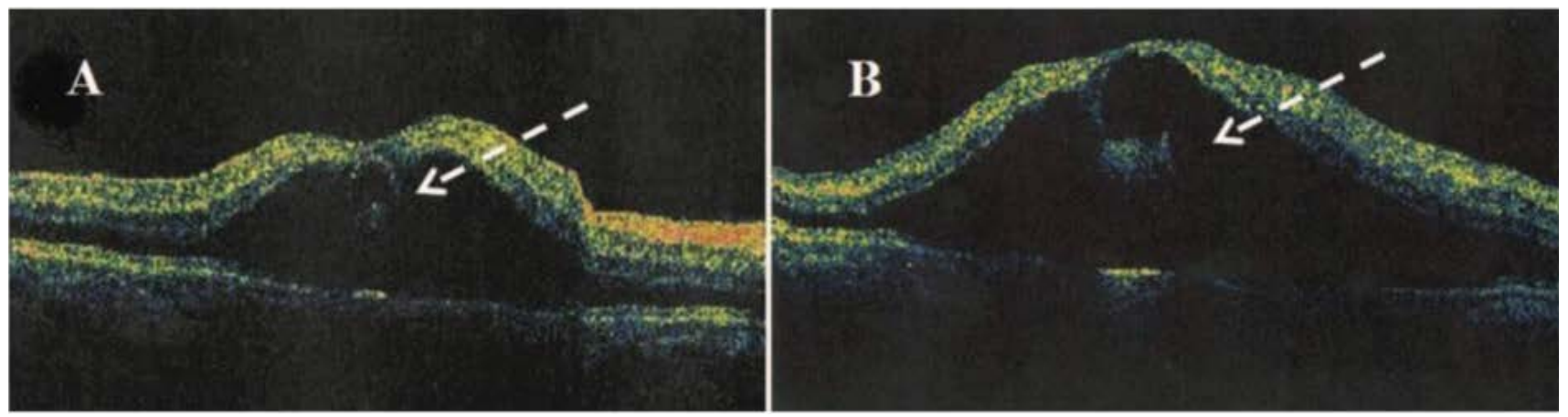

Figure 12: A) Optical coherence tomography showing large Type 2 CME with loss of normal foveal contour and B) Areas of low intraretinal reflectivity (dashed arrow) consistent with intraretinal cysts and fluid [96].
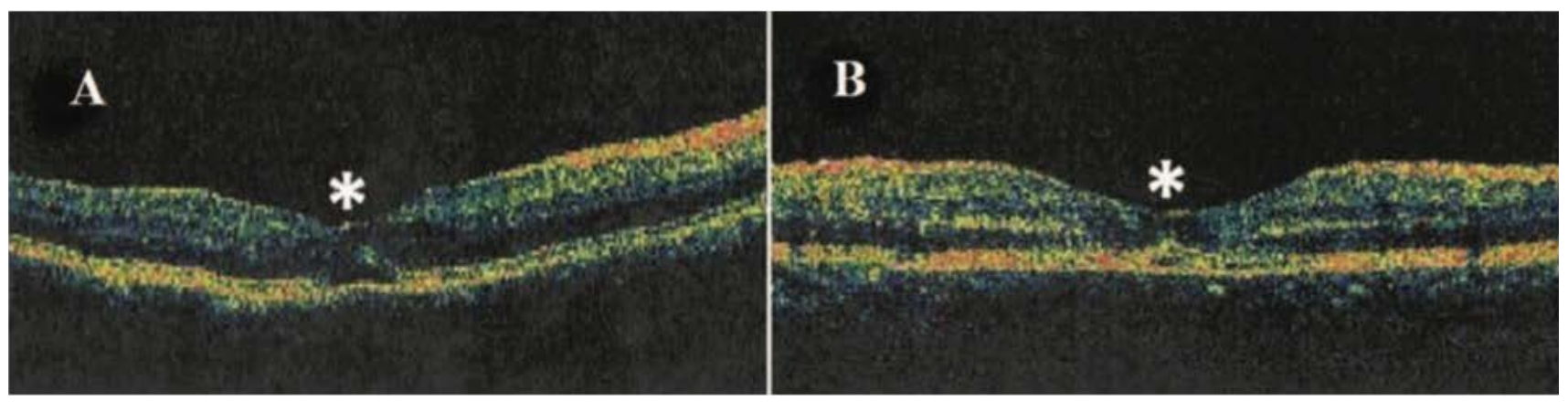

Figure 13: A) Optical coherence tomography showing cystic foveolitis (Type 3) characterized by subtle elevation and disruption of the foveal outer retina photoreceptors and/or retinal pigment epithelium layer as highlighted by asterisks $\left({ }^{*}\right)$ [96]. 
apy exist for ocular dengue manifestations. Treatment depends on the clinical response of patients, DENV serotype and severity of infection. A multimodal approach must be considered in these patients.

\section{Conclusion}

Dengue virus is vastly distributed around the globe, different serotypes are responsible for the millions of dengue infections worldwide. Early recognition of dengue's systemic and ocular symptoms prevents the detrimental complications that arise from the direct viral effect and host response to the virus. Complications vary from relatively benign skin petechiae and subconjunctival hemorrhage, to life threatening conditions such as shock syndrome. Ocular complications of dengue may occur as late as 5 months after infection resolution, and have severe visual consequences. Closely examination of patients with dengue and early detection of ocular findings may result in better clinical outcomes. Further research is needed to determine the precise moment and regimen strategies for achieving successful visual and systemic outcomes.

\section{Conflict of Interest}

No conflict of interest, either commercial or financial, interfered with the realization of this work.

\section{References}

1. Simmons CP, Farrar JJ, Vinh Chau N, Wills B (2012) Dengue. N Engl J Med 366: 1423-1432.

2. Guzman MG, Harris E (2015) Dengue. The Lancet 385: 453-465.

3. Kularatne SAM (2015) Dengue fever. BMJ 351: h4661.

4. Khetarpal N, Khanna I (2016) Dengue Fever: Causes, complications, and vaccine strategies. J Immunol Res 2016: 6803098 .

5. Bhatt S, Gething PW, Brady OJ, Messina JP, Farlow AW, et al. (2013) The global distribution and burden of dengue. Nature 496: 504-507.

6. Brady OJ, Gething PW, Bhatt S, Messina JP, Brownstein JS, et al. (2012) Refining the global spatial limits of dengue virus transmission by evidence-based consensus. PLoS Negl Trop Dis 6: e1760.

7. Stanaway JD, Shepard DS, Undurraga EA, Halasa YA, Coffeng LE, et al. (2016) The global burden of dengue: An analysis from the Global Burden of Disease Study 2013. Lancet Infect Dis 16: 712-723.

8. Halstead SB (1988) Pathogenesis of dengue: Challenges to molecular biology. Science 239: 476-481.

9. Kurane I (2007) Dengue hemorrhagic fever with special emphasis on immunopathogenesis. Comp Immunol Microbiol Infect Dis 30: 329-340.

10. Anderson KB, Gibbons RV, Cummings DAT, Nisalak A, Green S, et al. (2014) A shorter time interval between first and second dengue infections is associated with protection from clinical illness in a school-based cohort in Thailand. J Infect Dis 209: 360-368.

11. Montoya M, Gresh L, Mercado JC, Williams KL, Vargas MJ, et al. (2013) Symptomatic versus inapparent outcome in repeat dengue virus infections is influenced by the time interval between infections and study year. PLoS Negl Trop Dis 7: e2357.

12. Kuno G (1995) Review of the factors modulating dengue transmission. Epidemiol Rev 17: 321-335.

13. Halstead SB (1984) Selective primary health care: Strategies for control of disease in the developing world. XI. Dengue. Rev Infect Dis 6: 251-264.

14. Harrington LC, Scott TW, Lerdthusnee K, Coleman RC, Costero A, et al. (2005) Dispersal of the dengue vector aedes aegypti within and between rural communities. Am J Trop Med Hyg 72: 209-220.

15. Scott TW, Amerasinghe PH, Morrison AC, Lorenz LH, Clark GG, et al. (2000) Longitudinal studies of Aedes aegypti (Diptera: Culicidae) in Thailand and Puerto Rico: Blood feeding frequency. J Med Entomol 37: 89-101.

16. Gubler DJ (1997) Epidemic dengue and dengue hemorrhagic fever: A Global Public Health Problem in the $21^{\text {st }}$ Century. In: Michael Scheld W, Armstrong D, Hughes JM, Emerging Infections 1. Volume I, ASM Press, 1-14.

17. Caron M, Paupy C, Grard G, Becquart P, Mombo I, et al. (2012) Recent introduction and rapid dissemination of Chikungunya virus and Dengue virus serotype 2 associated with human and mosquito coinfections in Gabon, central Africa. Clin Infect Dis 55: e45-e53.

18. Gratz NG (2004) Critical review of the vector status of Aedes albopictus. Med Vet Entomol 18: 215-227.

19. Centers for Disease Control (CDC) (1989) Update: Aedes albopictus infestation--United States, Mexico. MMWR Morb Mortal Wkly Rep 38: 440, 445-446.

20. Wang E, Ni H, Xu R, Barrett AD, Watowich SJ, et al. (2000) Evolutionary relationships of endemic/epidemic and sylvatic dengue viruses. J Virol 74: 3227-3234.

21. Vaughn DW, Green S, Kalayanarooj S, Innis BL, Nimmannitya S, et al. (1997) Dengue in the early febrile phase: Viremia and antibody responses. J Infect Dis 176: 322-330.

22. Fukusumi M, Arashiro T, Arima $Y$, Matsui T, Shimada T, et al. (2016) Dengue sentinel traveler surveillance: Monthly and yearly notification trends among Japanese travelers, 2006-2014. PLoS Negl Trop Dis 10: e0004924.

23. Chen LH, Wilson ME (2004) Transmission of dengue virus without a mosquito vector: Nosocomial mucocutaneous transmission and other routes of transmission. Clin Infect Dis 39: e56-e60.

24. Stramer SL, Linnen JM, Carrick JM, Foster GA, Krysztof $D E$, et al. (2012) Dengue viremia in blood donors identified by RNA and detection of dengue transfusion transmission during the 2007 dengue outbreak in Puerto Rico. Transfusion 52: 1657-1666.

25. Sabino EC, Loureiro P, Lopes ME, Capuani L, McClure C, et al. (2016) Transfusion-transmitted dengue and associated clinical symptoms during the 2012 epidemic in Brazil. J Infect Dis 213: 694-702.

26. Sirinavin $S$, Nuntnarumit $P$, Supapannachart $S$, Boonkasidecha S, Techasaensiri C, et al. (2004) Vertical dengue infection: Case reports and review. Pediatr Infect Dis J 23: 1042-1047.

27. Carroll ID, Toovey S, Van Gompel A (2007) Dengue fever and pregnancy - a review and comment. Travel Med Infect Dis 5: 183-188.

28. Tan PC, Rajasingam G, Devi S, Omar SZ (2008) Dengue 
infection in pregnancy: Prevalence, vertical transmission, and pregnancy outcome. Obstet Gynecol 111: 1111-1117.

29. Jentes ES, Lash RR, Johansson MA, Sharp TM, Henry R, et al. (2016) Evidence-based risk assessment and communication: A new global dengue-risk map for travellers and clinicians. J Travel Med 23: taw062.

30. Brunette GW (2017) The Centers for Disease Control and Prevention. CDC Health Information for International Travel 2018. Oxford University Press, New York.

31. World Health Organization (2009) Dengue: Guidelines for Diagnosis, Treatment, Prevention and Control.

32. Endy TP, Chunsuttiwat S, Nisalak A, Libraty DH, Green S, et al. (2002) Epidemiology of inapparent and symptomatic acute dengue virus infection: A prospective study of primary school children in Kamphaeng Phet, Thailand. Am J Epidemiol 156: 40-51.

33. Trofa AF, DeFraites RF, Smoak BL, Kanesa-thasan N, King $A D$, et al. (1997) Dengue fever in US military personnel in Haiti. JAMA 277: 1546-1548.

34. Leder K, Torresi J, Brownstein JS, Wilson ME, Keystone JS, et al. (2013) Travel-associated illness trends and clusters, 2000-2010. Emerg Infect Dis 19: 1049-1073.

35. Yacoub S, Lam PK, Vu LHM, Le TL, Thanh Ha N, et al. (2016) Association of microvascular function and endothelial biomarkers with clinical outcome in dengue: An observational study. J Infect Dis 214: 697-706.

36. Muller DA, Depelsenaire ACI, Young PR (2017) Clinical and laboratory diagnosis of dengue virus infection. J Infect Dis 215: S89-S95.

37. Rigau-Pérez JG, Clark GG, Gubler DJ, Reiter P, Sanders EJ, et al. (1998) Dengue and dengue haemorrhagic fever. Lancet 352: 971-977.

38. Kalayanarooj S, Vaughn DW, Nimmannitya S, Green S, Suntayakorn S, et al. (1997) Early clinical and laboratory indicators of acute dengue illness. $\mathrm{J}$ Infect Dis 176: 313-321.

39. Halsey ES, Vilcarromero S, Forshey BM, Rocha C, Bazan I, et al. (2013) Performance of the tourniquet test for diagnosing dengue in Peru. Am J Trop Med Hyg 89: 99-104.

40. Mayxay M, Phetsouvanh R, Moore CE, Chansamouth V, Vongsouvath M, et al. (2011) Predictive diagnostic value of the tourniquet test for the diagnosis of dengue infection in adults. Trop Med Int Health 16: 127-133.

41. Srikiatkhachorn A, Krautrachue A, Ratanaprakarn W, Wongtapradit L, Nithipanya N, et al. (2007) Natural history of plasma leakage in dengue hemorrhagic fever: A serial ultrasonographic study. Pediatr Infect Dis J 26: 283-290.

42. Yacoub S, Wills B (2014) Predicting outcome from dengue. BMC Med 12: 147.

43. Lum LCS, Goh AYT, Chan PWK, El-Amin A-LM, Lam SK (2002) Risk factors for hemorrhage in severe dengue infections. J Pediatr 140: 629-631.

44. Yacoub S, Wills B (2015) Dengue: An update for clinicians working in non-endemic areas. Clin Med 15: 82-85.

45. Nimmannitya S (1987) Clinical spectrum and management of dengue haemorrhagic fever. Southeast Asian J Trop Med Public Health 18: 392-397.

46. Libraty DH, Young PR, Pickering D, Endy TP, Kalayanarooj $S$, et al. (2002) High circulating levels of the dengue virus nonstructural protein NS1 early in dengue illness correlate with the development of dengue hemorrhagic fever. J Infect Dis 186: 1165-1168.
47. Griffee MJ, Merkel MJ, Wei KS (2010) The role of echocardiography in hemodynamic assessment of septic shock. Crit Care Clin 26: 365-382.

48. Yacoub S, Wertheim H, Simmons CP, Screaton G, Wills B (2014) Cardiovascular manifestations of the emerging dengue pandemic. Nat Rev Cardiol 11: 335-345.

49. Shu P-Y, Chen L-K, Chang S-F, Su CL, Chien LJ, et al. (2004) Dengue Virus serotyping based on envelope and membrane and nonstructural protein NS1 serotype-specific capture immunoglobulin $\mathrm{M}$ enzyme-linked immunosorbent assays. J Clin Microbiol 42: 2489-2494.

50. Lanciotti RS, Calisher CH, Gubler DJ, Chang GJ, Vorndam AV (1992) Rapid detection and typing of dengue viruses from clinical samples by using reverse transcriptase-polymerase chain reaction. J Clin Microbiol 30: 545-551.

51. Deubel V, Laille M, Hugnot JP, Chungue E, Guesdon JL, et al. (1990) Identification of dengue sequences by genomic amplification: Rapid diagnosis of dengue virus serotypes in peripheral blood. J Virol Methods 30: 41-54.

52. Teoh B-T, Sam S-S, Tan K-K, Johari J, Danlami MB, et al. (2013) Detection of dengue viruses using reverse transcription-loop-mediated isothermal amplification. BMC Infect Dis 13: 387 .

53. Najioullah F, Viron F, Césaire R (2014) Evaluation of four commercial real-time RT-PCR kits for the detection of dengue viruses in clinical samples. Virol J 11: 164.

54. Shamala DS (2015) Laboratory diagnosis of dengue: A review. IMJM 14.

55. Gould EA, Solomon T (2008) Pathogenic flaviviruses. Lancet 371: 500-509.

56. Young PR, Hilditch PA, Bletchly C, Halloran W (2000) An antigen capture enzyme-linked immunosorbent assay reveals high levels of the dengue virus protein NS1 in the sera of infected patients. J Clin Microbiol 38: 1053-1057.

57. Alcon S, Talarmin A, Debruyne M, Falconar A, Deubel V, et al. (2002) Enzyme-linked immunosorbent assay specific to dengue virus type 1 nonstructural protein NS1 reveals circulation of the antigen in the blood during the acute phase of disease in patients experiencing primary or secondary infections. J Clin Microbiol 40: 376-381.

58. Avirutnan P, Punyadee N, Noisakran S, Komoltri C, Thiemmeca $S$, et al. (2006) Vascular leakage in severe dengue virus infections: A potential role for the nonstructural viral protein NS1 and complement. J Infect Dis 193: 1078-1088.

59. Talarmin A, Labeau B, Lelarge J, Sarthou JL (1998) Immunoglobulin A-specific capture enzyme-linked immunosorbent assay for diagnosis of dengue fever. J Clin Microbiol 36: 1189-1192.

60. Ahmed F, Mursalin H, Alam MT, Amin R, Sekaran SD, et al. (2010) Evaluation of ASSURE $®$ Dengue IgA rapid test using dengue-positive and dengue-negative samples. Diagn Microbiol Infect Dis 68: 339-344.

61. Khairallah M, Ben Yahia S, Attia S (2010) Arthropod vector-borne uveitis in the developing world. Int Ophthalmol Clin 50: 125-144.

62. Khairallah M, Chee SP, Rathinam SR, Attia S, Nadella V (2010) Novel infectious agents causing uveitis. Int Ophthalmol 30: 465-483.

63. Teoh SCB, Chan DPL, Laude A, Chee CKL, Lim TH, et al. (2006) Dengue chorioretinitis and dengue-related ophthalmic complications. Ocul Immunol Uveitis Found 9: 1-19. 
64. Chan DPL, Teoh SCB, Tan CSH, Nah GKM, Rajagopalan $\mathrm{R}$, et al. (2006) Ophthalmic complications of dengue. Emerg Infect Dis 12: 285-289.

65. Seet RCS, Quek AML, Lim ECH (2007) Symptoms and risk factors of ocular complications following dengue infection. $\mathrm{J}$ Clin Virol 38: 101-105.

66. Teoh SCB, Chan DPL, Nah GKM, Rajagopalan R, Laude $A$, et al. (2006) A re-look at ocular complications in dengue fever and dengue haemorrhagic fever.

67. Yip VC-H, Sanjay S, Koh YT (2012) Ophthalmic complications of dengue Fever: A systematic review. Ophthalmol Ther 1: 2 .

68. Hussain I, Afzal F, Shabbir A, Adil A, Zahid A, et al. (2012) Ophthalmic manifestation of dengue fever. An official journal of peshawar medical college 10: 93.

69. Kapoor HK, Bhai S, John M, Xavier J (2006) Ocular manifestations of dengue fever in an East Indian epidemic. Can J Ophthalmol 41: 741-746.

70. Mehta S, Mehta S, Jiandani P (2006) Ocular features of dengue septic shock (DSS). J Assoc Physicians India 54: 866.

71. Bacsal KE, Chee S-P, Cheng C-L, Flores JVP (2007) Dengue-associated maculopathy. Arch Ophthalmol 125: 501510.

72. Gupta A, Srinivasan R, Setia S, Soundravally R, Pandian DG (2009) Uveitis following dengue fever. Eye 23: 873-876.

73. Chhavi N, Venkatesh C, Soundararajan P, Gunasekaran D (2013) Unusual ocular manifestations of dengue fever in a young girl. Indian J Pediatr 80: 522-523.

74. Tabbara K (2012) Dengue retinochoroiditis. Ann Saudi Med 32: $530-533$

75. Sanjay S, Anilkumar A, Mahendradas P, Kawali A, Priya BV, et al. (2020) Inflammatory branch retinal artery and vein occlusion with panuveitis secondary to dengue fever. Indian J Ophthalmol 68: 1958-1960.

76. Lim W-K, Mathur R, Koh A, Yeoh R, Chee S-P (2004) Ocular manifestations of dengue fever. Ophthalmology 111: 2057-2064.

77. Su DH-W, Bacsal K, Chee S-P, Flores JVP, Lim WK, et al (2007) Prevalence of dengue maculopathy in patients hospitalized for dengue fever. Ophthalmology 114: 1743-1747.

78. Halstead SB (1980) Immunological parameters of togavirus disease syndromes. In: Robert Walter Schlesinger, The Togaviruses: Biology, Structure, Replication. Academic press, New York, 107-173.

79. Verma R, Sahu R, Holla V (2014) Neurological manifestations of dengue infection: A review. J Neurol Sci 346: 26-34.

80. Sanjay S, Wagle AM, Au Eong K-G (2009) Dengue optic neuropathy. Ophthalmology 116: 170.

81. Preechawat $P$, Poonyathalang A (2005) Bilateral optic neuritis after dengue viral infection. J Neuroophthalmol 25: 5152.

82. Wen KH, Sheu MM, Chung CB, Wang HZ, Chen CW (1989) The ocular fundus findings in dengue fever. Gaoxiong $\mathrm{Yi}$ Xue Ke Xue Za Zhi 5: 24-30.
83. Ramakrishnan R, Shrivastava S, Deshpande S, Patkar $P$ (2016) Anterior ischemic optic neuropathy following dengue fever. Oman J Ophthalmol 9: 160-163.

84. Boo YL, Lim SY, Chin PW, Hoo FK (2017) Bilateral optic neuritis with maculopathy: $A$ rare manifestation of dengue fever. Malays Fam Physician 12: 32-34.

85. Ramos JM, Tello A, Alzamora A, Ramón ML (2015) Optic neuritis in a traveler returning from Dominican Republic to Spain with dengue virus infection. J Travel Med 22: 133135.

86. Mohindra VK, Kumari A (2013) Unilateral optic neuritis associated with dengue fever. Delhi Journal of Ophthalmology 23: $293-294$.

87. Puccioni-Sohler M, Ornelas AMM, de Souza AS, Cabral-Castro MJ, TMA Ramos, et al. (2017) First report of persistent dengue-1-associated autoimmune neurological disturbance: Neuromyelitis optica spectrum disorder. J Neurovirol 23: 768-771.

88. Lana-Peixoto MA, Pedrosa D, Talim N, Amaral JMSS, Horta A, et al. (2018) Neuromyelitis optica spectrum disorder associated with dengue virus infection. J Neuroimmunol 318: $53-55$.

89. Miranda de Sousa A, Puccioni-Sohler M, Dias Borges A, Fernandes Adorno L, Papais Alvarenga M, et al. (2006) Post-dengue neuromyelitis optica: Case report of a Japanese-descendent Brazilian child. J Infect Chemother 12: 396-398.

90. de Silva NL, Weeratunga $P$, Umapathi $T$, Malavige $N$, Chang T (2019) Miller Fisher syndrome developing as a parainfectious manifestation of dengue fever: A case report and review of the literature. J Med Case Rep 13: 120.

91. Dalugama C, Shelton J, Ekanayake M, Gawarammana IB (2018) Dengue fever complicated with Guillain-Barré syndrome: A case report and review of the literature. J Med Case Rep 12: 137.

92. Ropper AH (1994) Miller Fisher syndrome and other acute variants of Guillain-Barré syndrome. Baillieres Clin Neurol 3: 95-106.

93. Gubler DJ (1998) Dengue and dengue hemorrhagic fever. Clin Microbiol Rev 11: 480-496.

94. Velaitham P, Vijayasingham N (2016) Central retinal vein occlusion concomitant with dengue fever. International Journal of Retina and Vitreous 2.

95. Kanungo S, Shukla D, Kim R (2008) Branch retinal artery occlusion secondary to dengue fever. Indian J Ophthalmol 56: 73-74.

96. Teoh SC, Chee CK, Laude A, Goh KY, Barkham T, et al. (2010) Optical coherence tomography patterns as predictors of visual outcome in dengue-related maculopathy. Retina 30: 390-398.

97. Mi H, Ho SL, Lim WK, Wong EP, Teoh SC (2015) Trends in patterns of posterior uveitis and panuveitis in a tertiary institution in Singapore. Ocul Immunol Inflamm 23: 329-338. 